\title{
Real-Time Distributed Strain Monitoring of a Railway Bridge during Train Passage by Using a Distributed Optical Fiber Sensor Based on Brillouin Optical Correlation Domain Analysis
}

\author{
Hyuk-Jin Yoon, ${ }^{1}$ Kwang-Yong Song, ${ }^{2}$ Chanyong Choi, ${ }^{1}$ \\ Hee-Seoung $\mathrm{Na}^{1}{ }^{1}$ and Jung-Seok Kim ${ }^{1}$ \\ ${ }^{1}$ Korea Railroad Research Institute, Uiwang 437-757, Republic of Korea \\ ${ }^{2}$ Department Of Physics, Chung-Ang University, Seoul 156-756, Republic of Korea \\ Correspondence should be addressed to Hyuk-Jin Yoon; scipio@krri.re.kr
}

Received 15 June 2016; Revised 2 September 2016; Accepted 8 September 2016

Academic Editor: Banshi D. Gupta

Copyright (c) 2016 Hyuk-Jin Yoon et al. This is an open access article distributed under the Creative Commons Attribution License, which permits unrestricted use, distribution, and reproduction in any medium, provided the original work is properly cited.

\begin{abstract}
This study demonstrates the monitoring of distributed strain of rail and girder of a railway bridge occurring during train passage over the bridge's entire section on a real-time basis by applying a developed distributed optical fiber sensor based on Brillouin Optical Correlation Domain Analysis (BOCDA). The distributed optical fiber sensor system and an algorithm to control as well as to analyze Brillouin gain spectrum signals were also developed. A single-mode optical fiber was attached in the longitudinal direction on the rail and the lower flange of the girder to be used as a sensing fiber of the BOCDA system. Changes in the girder's strain at the center point of the bridge during the passage of a commercial train were measured at $9 \mathrm{~Hz}$, and the accuracy of this measurement was validated by comparing the measured data with the data from strain gauge. In addition, the distributed strain of a girder and the rail with a length of $40.26 \mathrm{~m}$ was measured in real time with a spatial resolution of $31.1 \mathrm{~cm}$. Based on the results of the rail's strain distribution, the study could identify the location where excessive strain occurred due to an influence of unsupported sleepers on girder of the bridge.
\end{abstract}

\section{Introduction}

A bridge is a complex overpass structure consisting of various structural components including bridge deck, girders, piers, and bearings that allow passage over a river, valley, lowlying ground, or a road. Bridge structures recently are becoming increasingly larger, and this trend is enabled by advancements in design and construction technologies and convergence with IT including electrical and electronic techniques. In building a bridge structure, damage may occur during construction despite application of improved design theories and advanced construction techniques. Moreover, bridge structures that have been in use for a long time are exposed to harsh external conditions and thus are susceptible to damage, and sudden collapse as a result may lead to enormous damage. It is therefore necessary to evaluate the state and safety levels of each bridge member by performing nondestructive safety inspections regularly $[1,2]$.
Previous research mainly involved measuring behaviors of bridge members by attaching electrical strain gauges (ESGs) to the members in order to evaluate the maximum stress on them [3], but this method presented was vulnerable to electromagnetic noise and required wiring to support a larger number of strain gauges. To overcome such shortcomings, studies on the use of optical fiber sensors, which are unaffected by electromagnetic waves, to evaluate bridge behaviors have been widely carried out around the world $[4,5]$. In particular, the fiber Bragg grating (FBG) sensor allows simple measurement of disturbances such as strain by measuring shift of reflected wavelength, while the use of the wavelength division multiplexing technique also makes it possible to measure multiple points simultaneously by connecting several sensors with a single line [6]. However, this method also has limitations that a larger number of FBG sensors translate to greater cost and that it allows measurement only at the points where FBG sensors are attached. 
Recent studies have dealt with real-time measurement of strain over the entire section of a bridge by using a single line attached with optical fiber in a distributed optical fiber sensor, taking advantage of the intrinsic light scattering phenomenon occurring in the optical fiber $[7,8]$. Because this method uses optical fiber for optical communication as a sensor without requiring any additional process, it can dramatically reduce the cost of using multiple point-sensors. Despite this advantage, measurement using this method takes several minutes for signal processing and hence can be applied only to static measurement involving a vehicle stopped on a bridge, rather than to dynamic measurement of a running vehicle. However, in order to evaluate behaviors of bridge members, it is necessary to measure the distribution of strain over the entire section of a bridge during the passage of a vehicle.

This study suggests a method to measure the longitudinal distribution of strain over the entire section of a railway bridge during train passage by using a distributed optical fiber sensor based on a Brillouin Optical Correlation Domain Analysis (BOCDA). A tight-buffered single-mode optical fiber was attached in the longitudinal direction on the rail and girder as superstructures of the bridge to be used as a sensing fiber, while a BOCDA system of a high spatial resolution and high sampling rate was developed with optical components and electrical components for the monitoring of sensing fiber. The longitudinal strain distribution on the rail and girder was measured in real time when an actual train in commercial operation was passing over a bridge, and the center of the bridge was randomly chosen to measure strain responses over time at high-speed. To our knowledge, this is the first demonstration of using a distributed optical fiber sensor based on BOCDA in order to monitor the strain distribution of rail and girder as superstructures of a railway bridge that occurs during train passage.

\section{Principle of Distributed Optical Sensing Based on BOCDA}

An optical fiber can be utilized as a sensor for various physical variables owing to its unique attributes that are sensitive to changes in the external environment. In addition, due to its nature, a lengthy optical fiber can be embedded in a structure, which is advantageous for distributed measurement. Rayleigh, Brillouin, and Raman scatterings are dominant scattering phenomena in optical fibers which occur by linear or nonlinear interaction of light (i.e., photon) with local molecules. The Brillouin scattering is an inelastic scattering of light by a longitudinal acoustic wave propagating through the core of an optical fiber where the acoustic wave plays a role in moving Bragg grating. The optical frequency of the backscattered light by the Brillouin scattering is up- or downshifted from that of the incident light due to Doppler effect in which the sign is determined by the relative direction of the acoustic wave to that of light. The amount of frequency shift is called Brillouin frequency $\left(\nu_{B}\right)$ which is determined by the phase-matching condition of the scattering as follows [9]:

$$
v_{B}=\frac{2 n V_{a}}{\lambda}
$$

where $n, V_{a}$, and $\lambda$ are the refractive index of optical fiber, the acoustic velocity, and the optical wavelength, respectively. The Brillouin frequency is about $10.8 \mathrm{GHz}$ in a single-mode optical fiber at the telecom wavelength $(\lambda=1550 \mathrm{~nm})$. Distributed Brillouin sensors are operated by measuring the variation of local Brillouin frequencies in an optical fiber, which is a linear function of temperature and strain. The temperature and strain sensitivities of $\nu_{B}$ are about $1 \mathrm{MHz} /{ }^{\circ} \mathrm{C}$ and $0.05 \mathrm{MHz} / \mu \varepsilon$, respectively, in a conventional single-mode optical fiber [10]. While the Brillouin scattering takes place spontaneously by thermally excited acoustic waves in the optical fiber, one can also obtain much stronger scattering by a stimulated process when the acoustic wave is generated by the interference of two counterpropagating optical waves of different optical frequencies. The latter case is called stimulated Brillouin scattering (SBS). Distributed Brillouin sensors based on SBS provide much larger signal amplitude than spontaneous scattering-based ones while the light propagation from both ends of a sensing fiber is necessary.

Distributed Brillouin sensors may take different forms depending on the type of applied scattering process (spontaneous or stimulated) and the measurement domain (time, correlation, or frequency), represented by Brillouin Optical Time Domain Analysis (BOTDA), Brillouin Optical Time Domain Reflectometry (BOTDR), and Brillouin Optical Correlation Domain Analysis (BOCDA) systems [10-13]. In particular, the BOCDA shows unique advantages of high spatial resolution $(\sim \mathrm{mm})$, high sampling rate $(\sim \mathrm{kHz})$, and random access of sensing position, at the cost of limited measurement range, which can provide an efficient tool in short-range high-resolution distributed measurements [1315]. In a BOCDA system the Brillouin signal is generated by the SBS between counterpropagating pump and probe waves which are frequency-modulated by a sinusoidal RF wave. The spatial resolution $(\Delta z)$ and the sensing range $\left(d_{m}\right)$ of the measurement are determined by the modulation frequency $\left(f_{m}\right)$ and the modulation amplitude $(\Delta f)$ of the pump and probe waves by the following equations [13]:

$$
\begin{aligned}
& \Delta z=\frac{V_{g} \Delta \nu_{B}}{2 \pi f_{m} \Delta f}, \\
& d_{m}=\frac{V_{g}}{2 f_{m}},
\end{aligned}
$$

where $V_{g}$ and $\Delta v_{B}$ are the speed of light in optical fiber and the intrinsic linewidth of the Brillouin gain spectrum $(\sim 30 \mathrm{MHz})$, respectively.

The BOCDA used in this study involves observing Brillouin-scattered light in a correlation domain by using a continuous-wave light source. Figure 1 shows the fundamentals of the technique.

The observation is performed through the following steps:

(1) Pump and probe waves are launched in opposite directions inside an optical fiber where the optical frequencies of two waves are controlled to differ by $\Delta \nu$. 


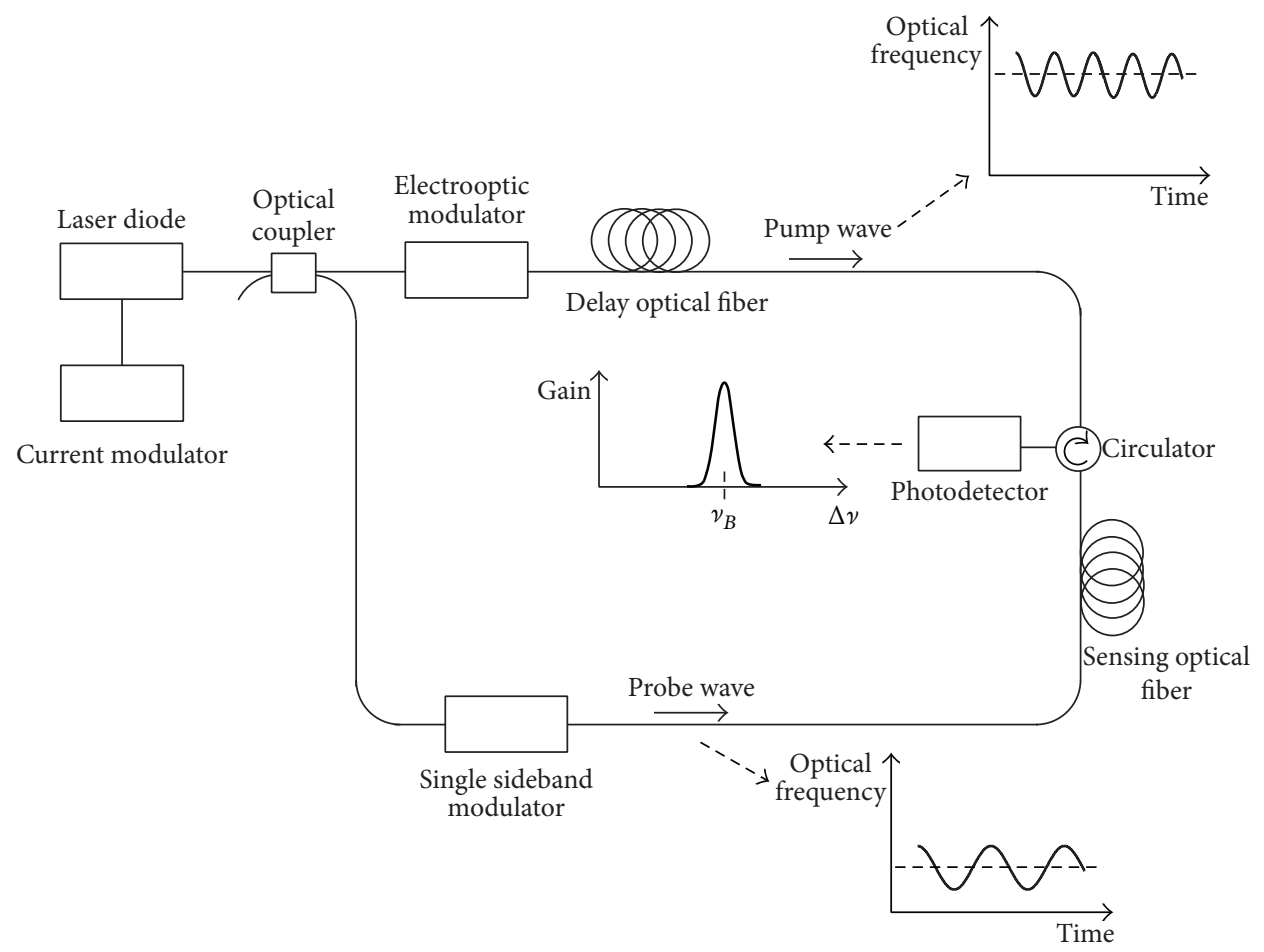

FIGURE 1: Schematic representation of the principles of the technique.

(2) A sinusoidal frequency modulation is applied commonly to the pump and probe waves to generate a local correlation peak at which the frequency difference between the pump and probe waves remains unchanged $(\Delta \nu)$ with time while it continuously changes elsewhere.

(3) $\Delta v$ is swept in the vicinity of the Brillouin frequency of the optical fiber so that the probe wave acquires the Brillouin gain only at the correlation position.

(4) Local Brillouin gain spectrum (BGS) at the correlation position is constructed from the power variation of the probe according to the sweep of $\Delta \nu$.

(5) Local $\nu_{B}$ is determined from the BGS which corresponds to the frequency of the maximum gain in the BGS.

(6) The measurement position (i.e., the position of the correlation peak) can be chosen as desired by varying the modulation frequency, and steps (3)-(5) are repeated.

The distributed strain $\varepsilon$ is calculated from the Brillouin frequency $v_{B}$ as follows:

$$
\varepsilon=\frac{1}{C_{S}} \cdot\left(\frac{\nu_{B}(\varepsilon)}{\nu_{B}(0)}-1\right),
$$

where the strain coefficient $C_{S}$ is 4.6 in our experiments.

In the previous work [16], we performed a feasibility study on longitudinal static strain monitoring of rail by the BOCDA where a strain-distribution profile of a $2.8 \mathrm{~m}$ rail under vertical load was successfully obtained. In the current

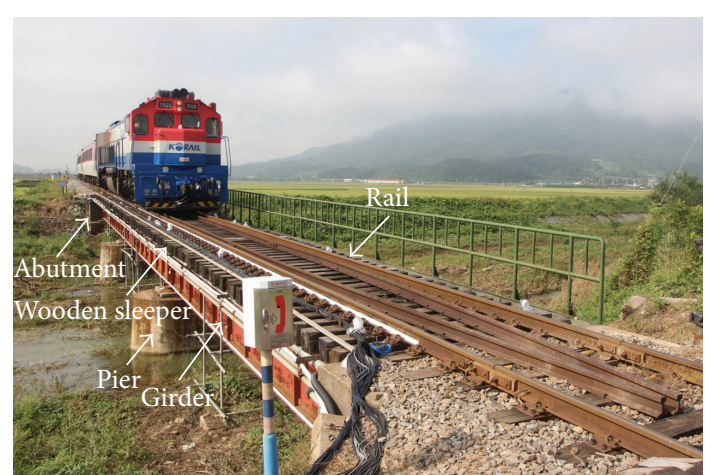

FIGURE 2: Structure of Cheong-ri Bridge.

work, we construct a portable BOCDA system and apply it to dynamic and distributed strain monitoring of a railway bridge during train passage.

\section{Bridge Description}

Cheong-ri Bridge is located between Cheong-ri Station and Oksan Station on a commercial railroad line operated by Korea Railroad Corporation. It is a typical ballastless railway girder bridge built over a stream shown in Figure 2, which can be standardized easily because of the uniform design.

Uniformity and standardization are advantages for maintaining bridges in a large transportation network [17]. On a weekday, a total of 10 railway vehicles including six passenger and sightseeing trains and cargo trains run on this line at a maximum speed of $90 \mathrm{~km} / \mathrm{h}$. 


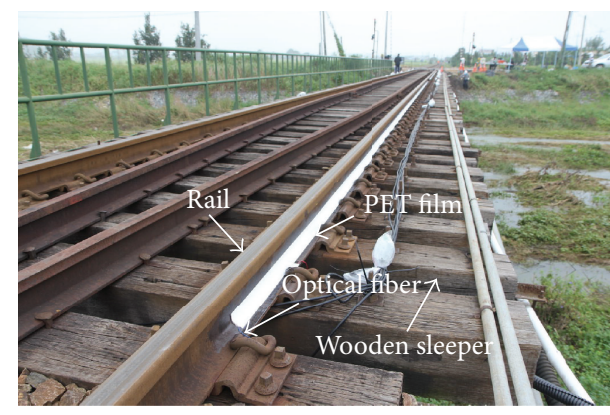

(a)

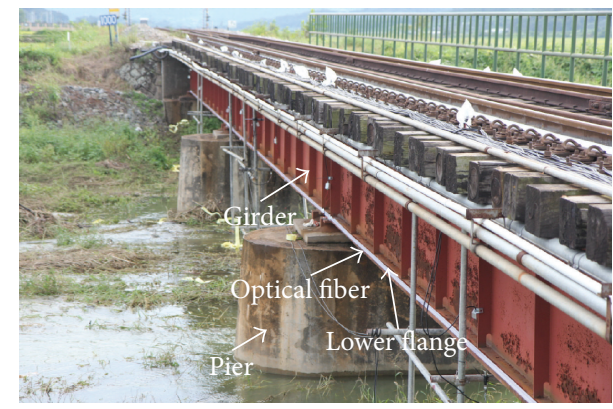

(b)

Figure 3: Direction and location of the optical fiber, (a) attached on the outer surface of the rail and (b) attached on the lower flange of the girder.

TABLE 1: Specifications of Cheong-ri Bridge.

\begin{tabular}{lc}
\hline Item & Size \\
\hline Total length & $40.26 \mathrm{~m}$ \\
Span between piers & $13.42 \mathrm{~m}$ \\
Design load & $\mathrm{LS}-22$ \\
Distance between centers of plate girder & $1.8 \mathrm{~m}$ \\
Height of steel web & $1.31 \mathrm{~m}$ \\
Rail type & $\mathrm{KS} 60$ \\
Dimensions of wooden sleeper & $230 \times 230 \times 3,000 \mathrm{~mm}$ \\
\hline
\end{tabular}

The design of the bridge superstructure is based on LS22 railway loading conditions. Rails and wooden sleepers are placed on plate girders without ballast, and the plate girders are laid upon two piers at the center of the bridge and on two abutments at both ends of the bridge through bridge bearing. The plate girders with an I-type cross section consist of three types of steel elements, namely, an upper flange, lower flange, and a steel web, and vertical stiffeners are welded with the outer steel web. Specifications of Cheong-ri Bridge are listed in Table 1.

\section{Experimental Setup}

The outer surface of the rail bottom on sleepers and the outer surface of the lower flange of the girder on piers to which optical fiber was to be attached were ground in the longitudinal direction with sandpaper to remove minute undulations and make the surfaces smooth, while dust on the surfaces was wiped off with ethanol. The optical fiber was placed in a straight line at a predetermined location in the longitudinal direction of the bridge and then attached to the surface with a $0.3 \mathrm{~mm}$ thick PET film as shown in Figure 3.

The optical fiber used is a single-mode fiber at the telecom wavelength of $1550 \mathrm{~nm}$ without any treatment for sensing with the internal structure shown in Figure 4 and is a tightbuffered fiber coated with Hytrel to allow easy transmission of strain applied from outside.

Table 2 lists more specific characteristics of the optical fiber used for this experiment.

To compare the data measured with the optical fiber, electric strain gauges (ESGs) were attached to the rail as

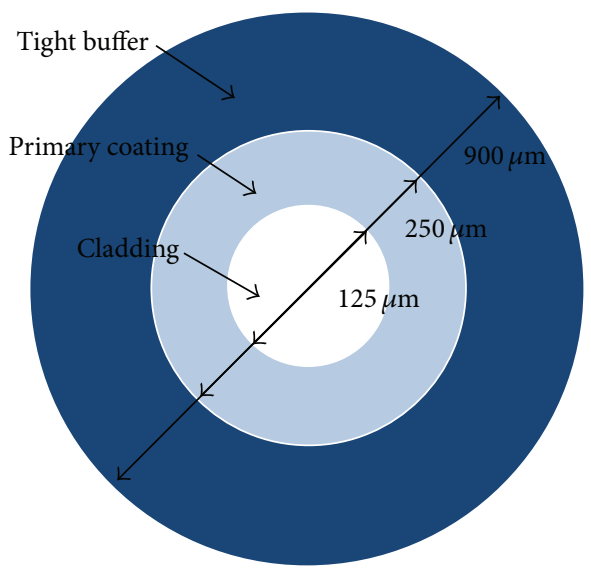

FIGURE 4: Structure of the optical fiber.

TABLE 2: Detailed specifications of the optical fiber.

\begin{tabular}{lll}
\hline Structure & Material & Specifications \\
\hline & & (i) Mode field diameter: \\
& $9.3 \pm 0.5 \mu \mathrm{m}$ \\
Optical fiber & Fiber & $\begin{array}{l}\text { (ii) Cladding diameter: } \\
125 \pm 0.5 \mu \mathrm{m}\end{array}$ \\
& & (iii) SM: G652D \\
\hline Primary coating & UV-cured acrylate & (i) Diameter: $250 \mu \mathrm{m}$ \\
\hline \multirow{2}{*}{ Tight buffer } & \multirow{2}{*}{ Hytrel } & (i) Diameter: $900 \pm 50 \mu \mathrm{m}$ \\
& & (ii) Hytrel 7246 \\
\hline
\end{tabular}

well as to the left and right of the lower flange, as shown in Figure 5.

The length of the ESGs used is $5 \mathrm{~mm}$, and the gauge factor is $2.08 \pm 1 \%$. The wheel weighing sensor and ESGs were individually connected to a data logger (CR9000X, Campbell Sci.) through lead lines and to a computer via PS-232C port for data collection.

The optical fiber attached to the rail and the girder was connected as a single line and then linked to the BOCDA system as shown in Figure 6(a).

The laser diode (LD) emits a continuous-wave light at a $1550 \mathrm{~nm}$ wavelength, and the output optical wave is frequency-modulated in a sinusoidal form by applying direct 


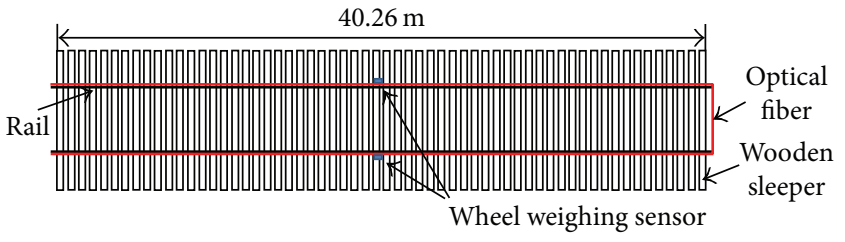

(a)

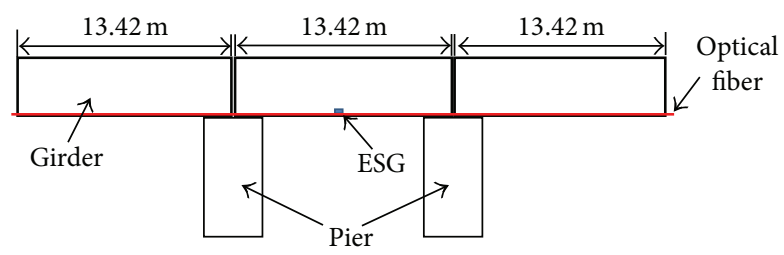

(b)

Figure 5: Sensor placement on Cheong-ri Bridge: (a) top view and (b) side view.

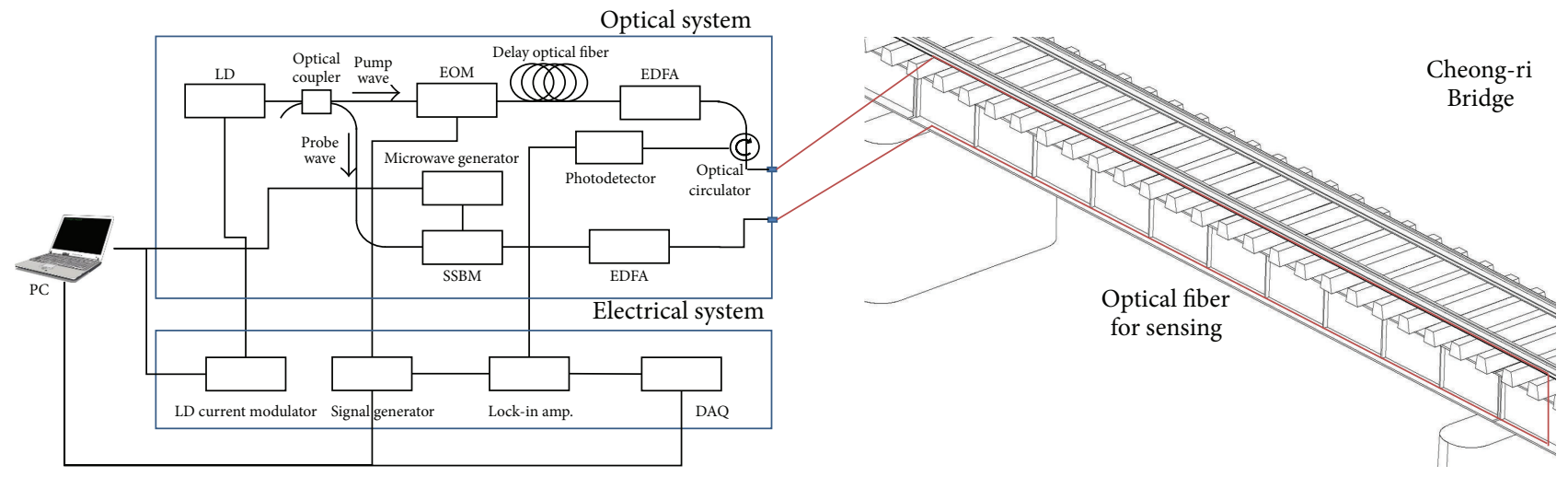

(a)

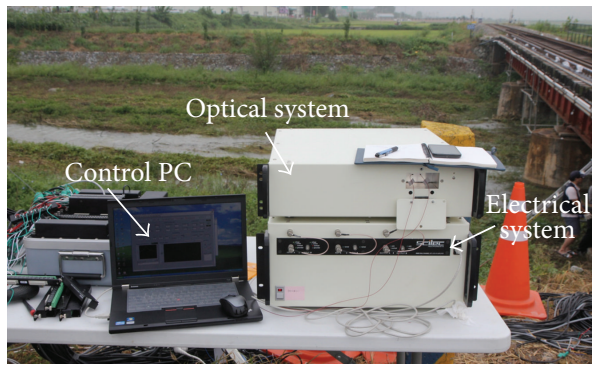

(b)

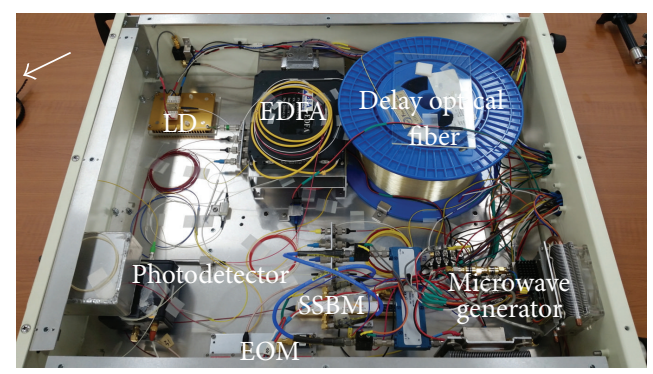

(c)

FIGURE 6: Experimental setup for the distributed strain monitoring of the Cheong-ri Bridge: (a) schematic diagram of the distributed optical fiber sensor system and the optical fiber attached on the bridge, (b) distributed optical fiber sensor system based on BOCDA method installed at the experimental site, and (c) configuration of the optical system with optical and electrical parts.

current modulation to the LD. The current modulation is controlled by the control PC for accurate control of the modulation frequency and amplitude as desired to locate the sensing position. The output from the LD is split by a 50/50 directional coupler into pump and probe arms. In the probe arm, the probe wave is generated by the sideband generation technique using a single sideband modulator (SSBM) and a microwave generator. In the pump arm, the pump wave is intensity-chopped by an electrooptic modulator (EOM) and launched into the optical fiber through a delay optical fiber, an erbium-doped fiber amplifier (EDFA), and an optical circulator. The intensity chopping by the EOM is applied at a fixed frequency which is also used as a reference frequency of a lock-in amplifier for lock-in detection of the BGS. The EDFA is used to amplify the pump wave up to $500 \mathrm{~mW}$ and the pump and probe waves are propagated through the optical fiber attached to the bridge in opposite direction to each other.
The frequency offset between the pump and probe waves is controlled by the microwave frequency applied to the SSBM, which is swept in the vicinity of the Brillouin frequency of the optical fiber for acquisition of local BGS at the sensing position.

With the above setup, the pump and probe waves move in the opposite direction from each other inside the optical fiber to induce Brillouin gain to the probe wave by SBS. The probe wave is amplified by the SBS at the correlation position as it goes through the sensing fiber, and then the amplitude is converted into electric signal by a photodetector. The signal from the photodetector is collected by a data acquisition board with the noise removed by a lock-in amplifier, and the local BGS at the target position is constructed from the control PC. In the lock-in detection only synchronous Brillouin gain signal by the chopped pump wave is passed and amplified by the lock-in amplifier with suppression of noises induced by intensity fluctuation of pump or probe 
TABLE 3: Specifications of the components used in the distributed optical fiber sensor system.

\begin{tabular}{|c|c|c|c|}
\hline System & Component & Parameter & Value \\
\hline \multirow{6}{*}{ Optical system } & LD & $\begin{array}{l}\text { Output power } \\
\text { Center wavelength } \\
\text { Linewidth }\end{array}$ & $\begin{array}{c}80 \mathrm{~mW} \\
1550.12 \mathrm{~nm} \\
1 \mathrm{MHz}\end{array}$ \\
\hline & SSBM & $\begin{array}{l}\text { Modulation speed } \\
\text { Drive voltage } \\
\text { Loss } \\
\text { Max. input power }\end{array}$ & $\begin{array}{c}10 \mathrm{Gbit} / \mathrm{s} \\
\leq 3.5 \mathrm{~V}(\text { port } \mathrm{A}, \mathrm{B}), \leq 7 \mathrm{~V}(\text { port } \mathrm{C}) \\
-18 \mathrm{dBm} \\
10 \mathrm{dBm}\end{array}$ \\
\hline & EOM & $\begin{array}{l}\text { Modulation speed } \\
\text { Drive voltage } \\
\text { Optical bandwidth } \\
\text { Max. input power }\end{array}$ & $\begin{array}{l}10 \mathrm{Gbit} / \mathrm{s} \\
\leq 4 \mathrm{~V} \mathrm{pp} \\
\geq 8 \mathrm{GHz} \\
10 \mathrm{dBm}\end{array}$ \\
\hline & Microwave generator & $\begin{array}{l}\text { Frequency range } \\
\text { Sweep time } \\
\text { Max. power }\end{array}$ & $\begin{array}{c}10 \sim 12 \mathrm{GHz} \\
\geq 10 \mathrm{~ms} \\
16 \mathrm{dBm}\end{array}$ \\
\hline & EDFA & $\begin{array}{c}\text { Input power } \\
\text { Max. output power } \\
\text { Operating wavelength }\end{array}$ & $\begin{array}{l}-6 \sim 3 \mathrm{dBm} \\
27 \mathrm{dBm} \\
1528 \sim 1562 \mathrm{~nm}\end{array}$ \\
\hline & Photodetector & $\begin{array}{l}3 \mathrm{~dB} \text { bandwidth } \\
\text { Max. input power }\end{array}$ & $\begin{array}{c}\mathrm{DC} \sim 125 \mathrm{MHz} \\
-15 \mathrm{dBm} \\
\end{array}$ \\
\hline \multirow{3}{*}{ Electrical system } & LD current modulator & $\begin{array}{l}\text { Max. input current } \\
\text { Current modulation freq. } \\
\text { Current modulation voltage }\end{array}$ & $\begin{array}{c}300 \mathrm{~mA} \\
\mathrm{DC} \sim 20 \mathrm{MHz} \\
\pm 10 \mathrm{~V} \mathrm{pp}\end{array}$ \\
\hline & Lock-in amplifier & $\begin{array}{c}\text { Reference frequency } \\
\text { Channel }\end{array}$ & $\begin{array}{l}\text { Max. } 200 \mathrm{kHz} \\
\text { Dual CH }\end{array}$ \\
\hline & DAQ & $\begin{array}{c}\text { Speed } \\
\text { Analogue input }\end{array}$ & $\begin{array}{l}\text { 12-bit ADC, } 1 \mathrm{MHz} \text { sampling } \\
2 \text { channels }\end{array}$ \\
\hline
\end{tabular}

waves from different origins. The local Brillouin frequency is obtained by the peak search process of the control PC, and the applied strain is calculated from the changes of the Brillouin frequency by using (3). Table 3 lists specifications of the components to develop the distributed optical fiber sensor system shown in Figure 6(b).

Figure 7 shows the control PC's algorithm for controlling the components of the BOCDA system and for processing Brillouin gain spectrum signals.

To control the components of the BOCDA system, the components must be initialized first and then the length information of the optical fiber attached on the bridge needs to be entered. Then the location to start and end measurement must be set. Based on the measurement location of the optical fiber, current, modulation voltage, and modulation width of LD current modulator are adjusted to configure the modulation frequency of the LD. In addition, the range of the acquisition frequency of the Brillouin gain spectrum is configured by adjusting the sweep time and sweep frequency of the microwave generator, and the filter and the chopping frequencies of the lock-in amplifier are configured. In the processing of local BGS signals a nonlinear approximate function such as a Gaussian function and a Lorentzian function is configured, and the Brillouin frequency is extracted through curve fitting. Strain is calculated from changes in the extracted Brillouin frequency. The algorithm for the control PC was implemented by using LabVIEW.

The BOCDA system implemented in this study modulates the frequency of the light emitted from a continuouswave light source by using EOM, allowing safe and stable modulation of optical signals without causing an overload of the light source or changes in the light intensity. In addition, because this system does not use optical pulses for distributed sensing, the spatial resolution is not limited by the pulse like pulse-based systems, allowing selection of a particular section for measurement at a high repetition rate. Thus, this system can be applied to the distributed monitoring of disturbances such as strain in a fast and efficient manner.

\section{Results and Discussion}

The train used for this study's experiment is made up of eight cars in total including one diesel locomotive, one generator car, and six passenger cars. It is the Mugunghwa train operating on a commercial route and is shown in Figure 8.

The diesel locomotive pulls the passenger cars and the generator car by using thrust as its driving force and is heavier than a passenger car as it is equipped with a diesel engine, a driving system, and a fuel tank [18]. The weight of the diesel locomotive is supported by two bogies, each consisting of three axles, in the front and in the rear. Meanwhile, two bogies, each consisting of two axles, support the weight of the generator car and passenger cars in the front and in the rear.

Figure 9 shows the wheel weight of the Mugunghwa train during its passage measured by a wheel weighing sensor attached to the rail, as illustrated in Figure 5.

The six wheel weights displayed on the far left of Figure 9 are from the locomotive and they are averagely $98.76 \mathrm{kN}$ each. The weights of the generator car and passenger cars are averagely $49.97 \mathrm{kN}$ each or about a half of that of the 


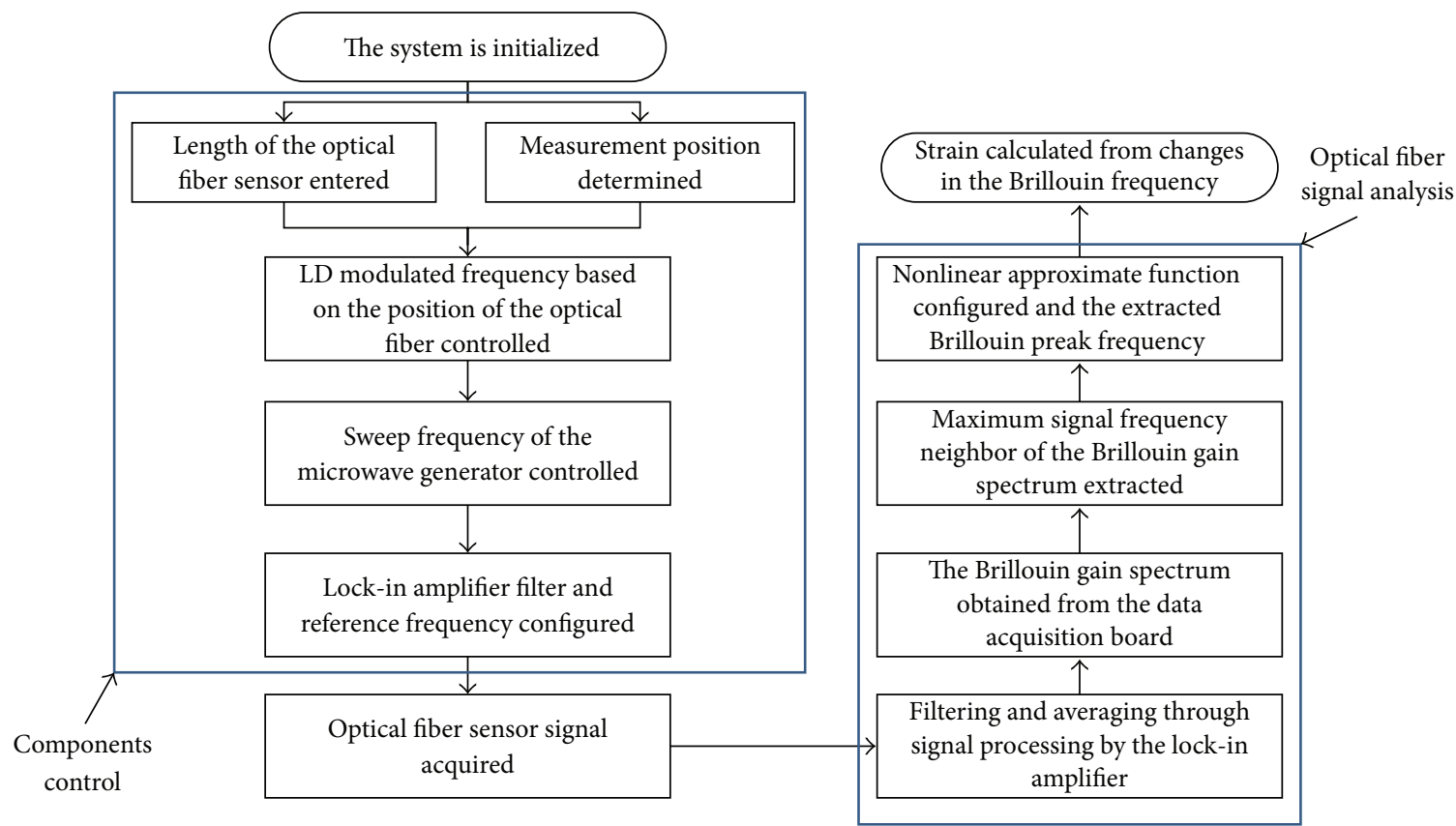

FIGURE 7: Operation and data processing steps for controlling the developed BOCDA system.

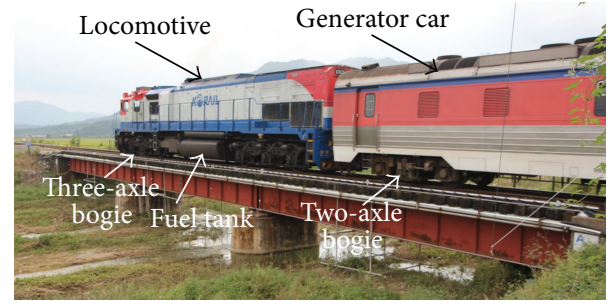

FIgURE 8: The Mugunghwa train used for the study's experiment at Cheong-ri Bridge.

locomotive. Because each passenger car had different passenger numbers and cargo volumes, the wheel weights varied from one passenger car to another. The wheel weights of the generator car and passenger cars showed little difference.

The Brillouin gain spectrum of the optical fiber attached on the girder at the middle of the bridge by sweeping the microwave generator from $10.5 \mathrm{GHz}$ to $11.1 \mathrm{GHz}$ with $30 \mathrm{~ms}$ sweeping time when the train passed over the Cheong-ri Bridge is shown in Figure 10. It should be noted that while the sweep time of $\Delta v$ was $30 \mathrm{~ms}$ two times of measurement applying orthogonal polarization states of pump wave were needed to avoid a possible polarization-dependent signal fading. So, total measurement time for a single position was about $100 \mathrm{~ms}$ including the time for signal processing for the Brillouin frequency determination with the measured BGS. The change of the measurement position by varying the modulation frequency of the laser took additional $10 \mathrm{~ms}$, so the overall sampling rate of local BGS measurement was $9 \mathrm{~Hz}$.

The portion of Brillouin frequency shift was within $0.01 \mathrm{GHz}$ over 12 seconds. The strain was calculated by using (3) based on the changes in the Brillouin frequency as depicted in Figure 11.

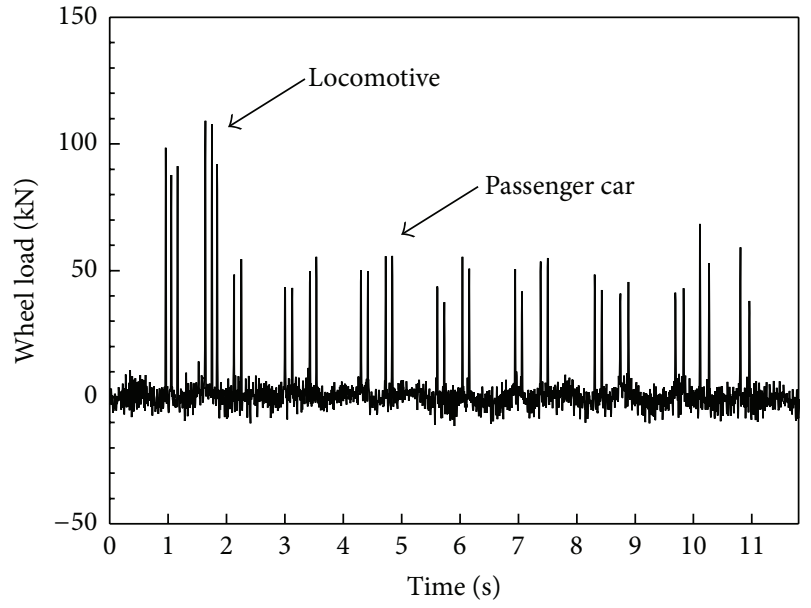

FIGURE 9: Wheel weight of the Mugunghwa train during its passage measured at the rail.

The train passed at about $15 \mathrm{~km} / \mathrm{h}$. The two peaks shown on the far left of Figure 12 represent the strain that occurred at the girder when the locomotive passed the bridge, and it was approximately $200 \mu \varepsilon$. Meanwhile, the strain that occurred during the passage of the passenger cars and the generator car was about $100 \mu \varepsilon$. This is attributable to the difference in wheel weights between the engine locomotive and the passenger cars [19]. The variable cycle of the peaks was caused by the difference in distance between the three-axle bogies of the locomotive and the two-axle bogies of the passenger car, as shown in Figure 8. The measured frequency of the distributed optical fiber sensor system was $9 \mathrm{~Hz}$, whereas the strain resolution was $\pm 15 \mu \varepsilon$. A dynamic data logger (CR9000X, Campbell Sci.) was used at a separate channel to 


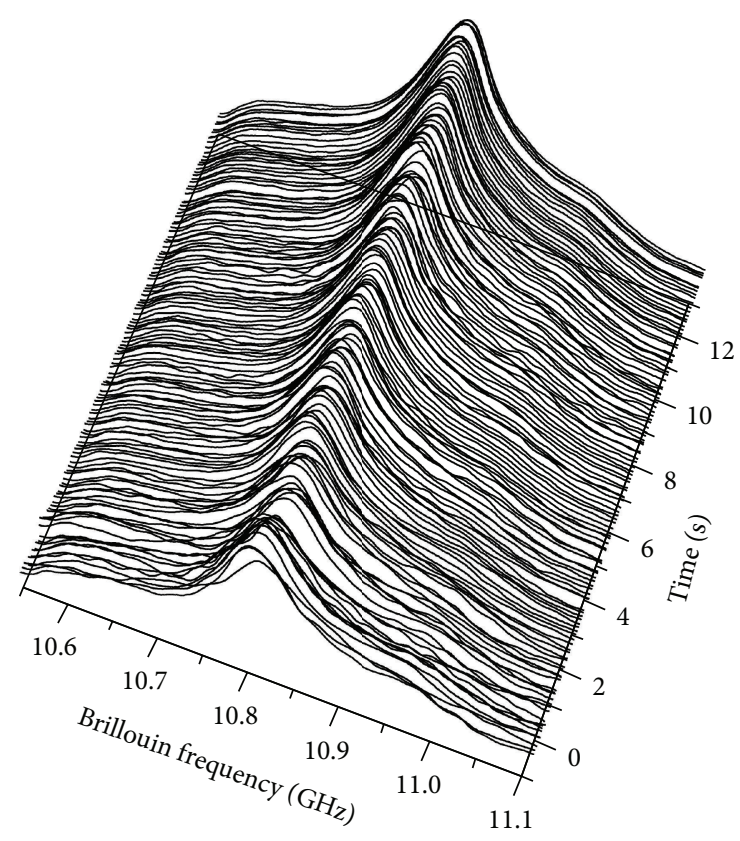

FIGURE 10: The BGS of the distributed optical fiber attached on the girder during the train passage.

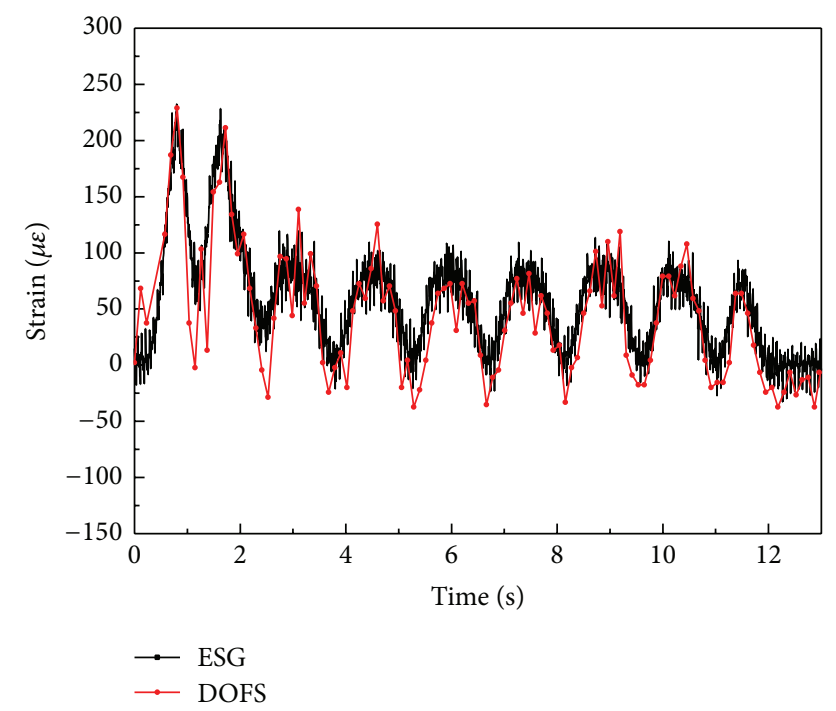

FIGURE 11: The strain of the girder at the center of the bridge during train passage measured with the distributed optical fiber sensor and the ESGs.

perform measurement with ESGs. The data measured with the distributed optical fiber sensor match well with the data measured with ESGs, confirming that the distributed optical fiber sensor could sufficiently measure changes in the strain of a girder during a train's passage. The partially different strain measured with the DOFS and ESG was complexly caused by the strain resolution of the DOFS relatively lower than ESG and a slight difference in the measurement location and direction between the DOFS and ESG installed in the experiment as shown in Figure 3(b).

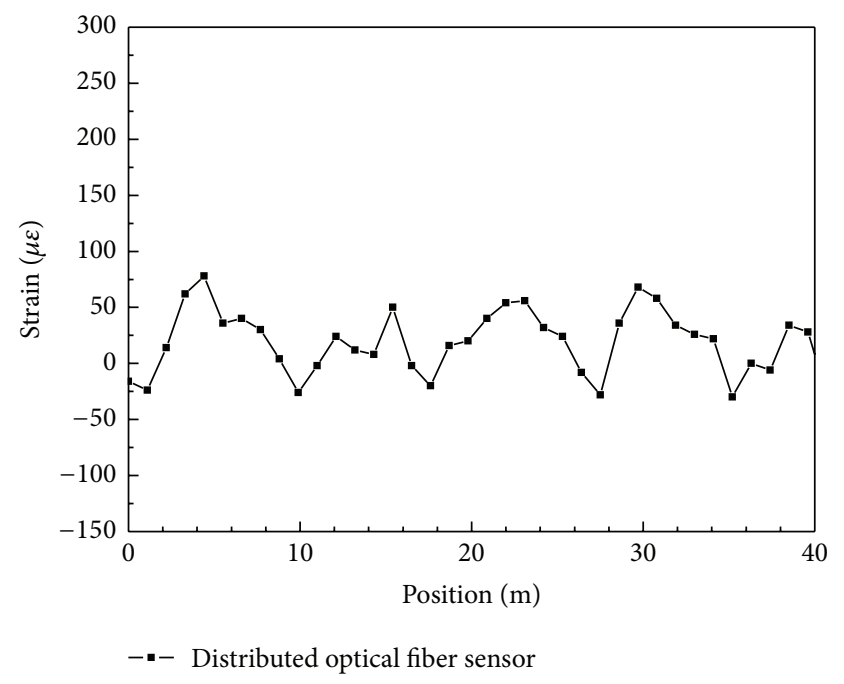

FIGURE 12: Strain distribution of the girder measured in the longitudinal direction by using the distributed optical fiber sensor during train passage.

Figure 12 shows the distribution of the strain measured in the longitudinal direction of the bridge by using the optical fiber sensor attached to the girder.

The spatial resolution was $31.1 \mathrm{~cm}$, and the measurement was performed over a length of $40.26 \mathrm{~m}$ at intervals of $1.1 \mathrm{~m}$. The strain distribution at different positions was obtained from changes in the Brillouin frequency of the optical fiber before train passage and during train passage. Because the location where the train's wheel weight is applied shifts as the train passed through the bridge, the longitudinal strain of the girder also exhibited dynamic changes accordingly within a range of strain in Figure 11. It should be noted that the distributed measurement of the 38 points in Figure 12 took $4.2 \mathrm{sec}$ with the single point sampling rate of $9 \mathrm{~Hz}$, which was sufficient considering the time required for the train passage on the bridge was about $10 \mathrm{sec}$.

In addition, Figure 13 shows the Brillouin frequency and the distribution of the strain measured in the longitudinal direction of the bridge by using the optical fiber sensor attached to the rail.

During train passage, rails are bouncing up and down because of the elasticity of wooden sleepers with the result that longitudinal strain of the rail changes within the negative and positive value. The measured strain on the rail was distributed within a range of $-98 \mu \varepsilon$ to $144 \mu \varepsilon$ and showed the same tendency on the girder as that illustrated in Figure 12. However, at the $27.5 \mathrm{~m}$ point, a particularly high value outside the range of $222 \mu \varepsilon$ was shown. This is because, as shown in Figure 14, the wooden sleepers are not tightly supported on top of the girder but there is a gap with a length of $1.5 \mathrm{~cm}$ between the sleepers and the girder, which may have caused an excessive strain when the train was passing this point.

Wooden sleepers, once installed, shrink at different rates from one another over time, resulting in different thicknesses among them. Thus, if a gap exists between the sleepers and the girder due to the aforementioned phenomenon, a huge 


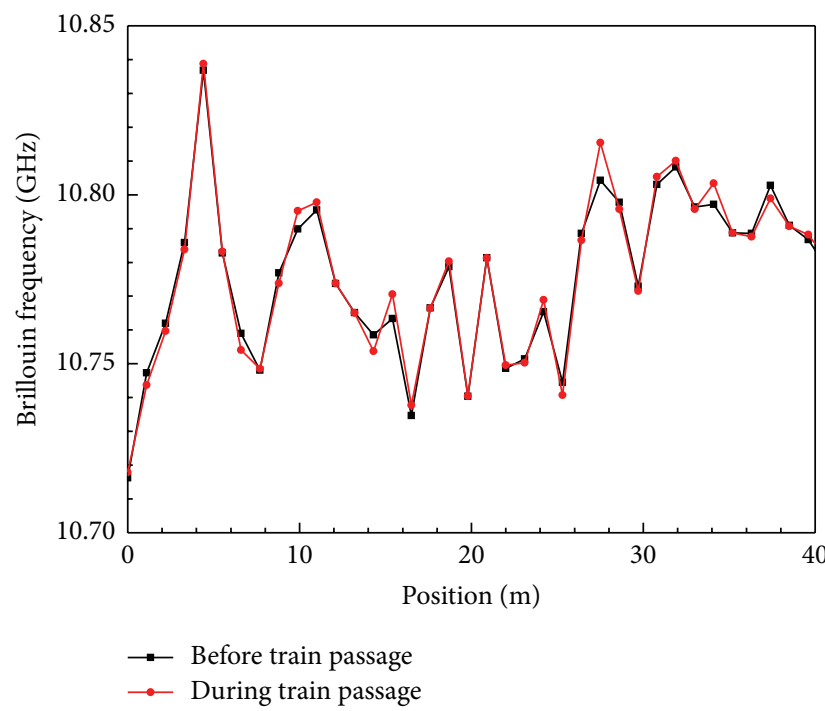

(a)

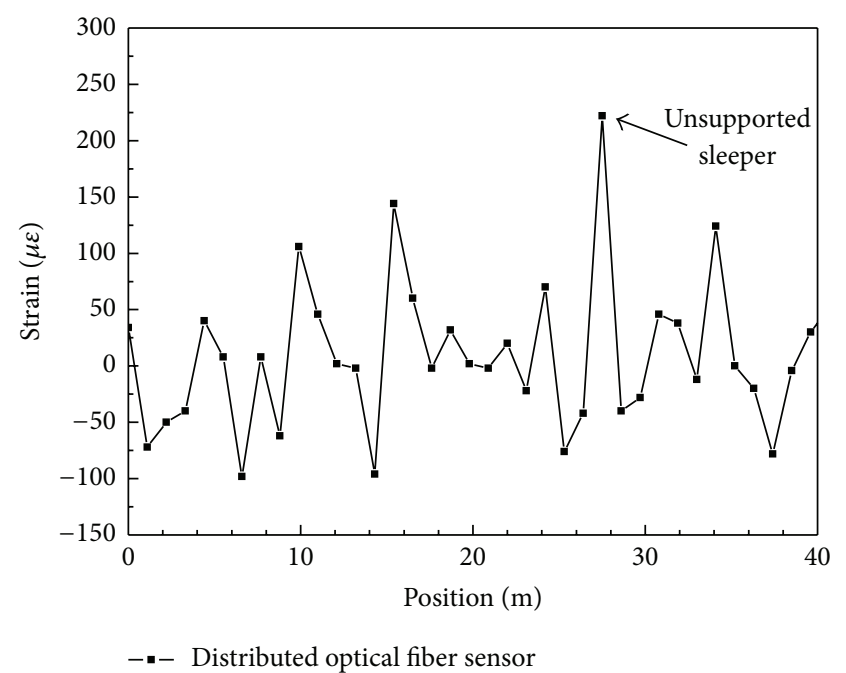

(b)

FIGURE 13: Brillouin frequency and strain distribution on the rail in the longitudinal direction of the bridge by using the distributed optical fiber sensor: (a) changes in the Brillouin frequency of the optical fiber attached to the rail before and during the train passage and (b) longitudinal strain distribution of the rail based on the bridge position during train passage.

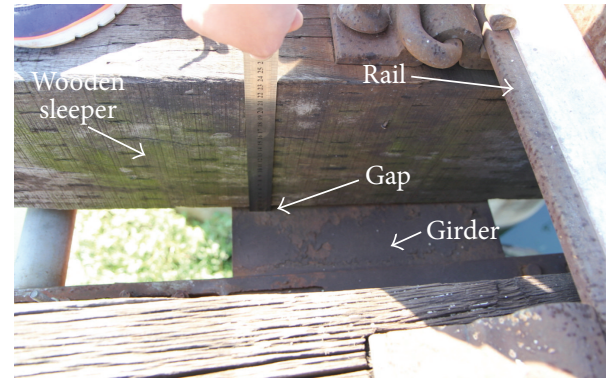

FIGURE 14: Unsupported sleeper which has a gap between the wooden sleeper and the girder.

impact load occurs upon a train passage, possibly leading to damage and deformation on the rails [20]. Moreover, fast deformation of the rails may undermine the safety of a running train while also weakening ride comfort.

With the above experiment, the distribution of strain on the rail and girder as superstructures of the experimental railway bridge was monitored during train passage in real time by using a distributed optical fiber sensor, while the location of a gap between the bridge's wooden sleepers and girder could be detected as well.

\section{Conclusion}

This study proposed a distributed optical fiber sensor system based on BOCDA, which is considered the most appropriate type to measure the distribution of longitudinal strain occurring at the rail and the girder as superstructures of a railway bridge during a train passage, and an experiment was carried out to verify the performance of developed sensor system. The BOCDA system was implemented based on the SBS between pump and probe waves localized by frequency modulation of a light source with continuous waves. Also an algorithm is developed in this study to control the system as well as to process signals from the Brillouin gain spectrum.

A tight-buffered single-mode optical fiber attached on the rail and girder of the experimental bridge was used as a sensor to measure the distribution of strain occurring during a train's passage on a real-time basis. From the strain of the girder measured at the center of the bridge, strain responses by the diesel locomotive and passenger cars were recognized separately, and they were confirmed to match the data from strain gauges. In addition, the strain distribution of the girder and rail in the longitudinal direction of the bridge was measured. From this outcome, the study could identify certain points on the rail where excessive strain occurred during the train passage, and this was due to a gap between the bridge's wooden sleepers and girder.

The BOCDA system implemented in this study is seldom affected by intensity noises during the measurement, which eliminates the need for repeated measurements to obtain averaged data. Less time is accordingly required for signal processing, making high-speed, distributed measurement possible. Furthermore, because the location where BGS is obtained can be selected at random, any point on a railway bridge can be chosen for high-speed measurement. The system proposed in this study thus can be highly useful in large-scale civil engineering structures.

\section{Competing Interests}

The authors declare that they have no competing interests. 


\section{Acknowledgments}

This research was supported by a grant (14SCIP-B06598502) from the Smart Civil Infrastructure Research Program funded by the Ministry of Land, Infrastructure and Transport (MOLIT) of the Korean government and the Korea Agency for Infrastructure Technology Advancement (KAIA).

\section{References}

[1] A. Au, C. Lam, and B. Tharmabala, "Investigation of shear resistance of steel bridge girders by load testing and monitoring of load response data under highway traffic conditions," Canadian Journal of Civil Engineering, vol. 36, no. 3, pp. 449-462, 2009.

[2] M. E. E. Jemli, R. Karoumi, and F. Lanaro, "Monitoring of the new Arsta railway bridge using traditional and fiber optic sensors," in Proceedings of the Smart Structures and Materials 2003: Smart Systems and Nondestructive Evaluation for Civil Infrastructures, vol. 5057 of Proceedings of SPIE, pp. 279-288, 2003.

[3] M. R. Chowdhury and J. C. Ray, "Accelerometers for bridge load testing," NDT and E International, vol. 36, no. 4, pp. 237-244, 2003.

[4] R. C. Tennyson, A. A. Mufti, S. Rizkalla, G. Tadros, and B. Benmokrane, "Structural health monitoring of innovative bridges in Canada with fiber optic sensors," Smart Materials and Structures, vol. 10, no. 3, pp. 560-573, 2001.

[5] G. Kister, R. A. Badcock, Y. M. Gebremichael et al., "Monitoring of an all-composite bridge using Bragg grating sensors," Construction and Building Materials, vol. 21, no. 7, pp. 1599-1604, 2007.

[6] H.-J. Yoon, D. M. Costantini, H. G. Limberger, R. P. Salathé, C.G. Kim, and V. Michaud, "In situ strain and temperature monitoring of adaptive composite materials," Journal of Intelligent Material Systems and Structures, vol. 17, no. 12, pp. 1059-1067, 2006.

[7] A. Minardo, R. Bernini, L. Amato, and L. Zeni, "Bridge monitoring using brillouin fiber-optic sensors," IEEE Sensors Journal, vol. 12, no. 1, pp. 145-150, 2012.

[8] J. He, Z. Zhou, and O. Jinping, "Optic fiber sensor-based smart bridge cable with functionality of self-sensing," Mechanical Systems and Signal Processing, vol. 35, no. 1-2, pp. 84-94, 2013.

[9] G. P. Agrawal, Nonlinear Fiber Optics, Academic Press, San Diego, Calif, USA, 2nd edition, 1995.

[10] M. Niklès, L. Thévenaz, and P. A. Robert, "Brillouin gain spectrum characterization in single-mode optical fibers," Journal of Lightwave Technology, vol. 15, no. 10, pp. 1842-1851, 1997.

[11] X. Bao, M. DeMerchant, A. Brown, and T. Bremner, "Tensile and compressive strain measurement in the lab and field with the distributed Brillouin scattering sensor," Journal of Lightwave Technology, vol. 19, no. 11, pp. 1698-1704, 2001.

[12] M. N. Alahbabi, Y. T. Cho, and T. P. Newson, "150-km-range distributed temperature sensor based on coherent detection of spontaneous Brillouin backscatter and in-line Raman amplification," Journal of the Optical Society of America B: Optical Physics, vol. 22, no. 6, pp. 1321-1324, 2005.

[13] K. Hotate and T. Hasegawa, "Measurement of Brillouin gain spectrum distribution along an optical fiber using a correlationbased technique-proposal, experiment and simulation," IEICE Transactions on Electronics, vol. 83, no. 3, pp. 405-412, 2000.
[14] K. Y. Song, Z. He, and K. Hotate, "Distributed strain measurement with millimeter-order spatial resolution based on Brillouin optical correlation domain analysis," Optics Letters, vol. 31, no. 17, pp. 2526-2528, 2006.

[15] K. Y. Song and K. Hotate, "Distributed fiber strain sensor with 1-kHz sampling rate based on Brillouin optical correlation domain analysis," IEEE Photonics Technology Letters, vol. 19, no. 23, pp. 1928-1930, 2007.

[16] H.-J. Yoon, K.-Y. Song, J.-S. Kim, and D.-S. Kim, "Longitudinal strain monitoring of rail using a distributed fiber sensor based on Brillouin optical correlation domain analysis," NDT and E International, vol. 44, no. 7, pp. 637-644, 2011.

[17] J. Zhao and D. Tonias, Bridge Engineering, McGraw-Hill, New York, NY, USA, 3rd edition, 2012.

[18] M. J. Hapeman, J. Long, and D. L. Plette, "Diesel electric locomotive propulsion systems-a look into the future," IEEE Transactions on Industry Applications, vol. 22, no. 3, pp. 495501, 1986.

[19] R. Karoumi, J. Wiberg, and A. Liljencrantz, "Monitoring traffic loads and dynamic effects using an instrumented railway bridge," Engineering Structures, vol. 27, no. 12, pp. 1813-1819, 2005.

[20] J. Shi, A. H. Chan, and M. P. N. Burrow, "Influence of unsupported sleepers on the dynamic response of a heavy haul railway embankment," Proceedings of the Institution of Mechanical Engineers Part F: Journal of Rail and Rapid Transit, vol. 227, no. 6, pp. 657-667, 2013. 


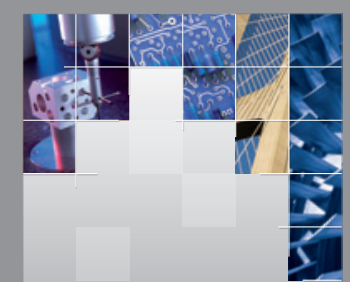

\section{Enfincering}
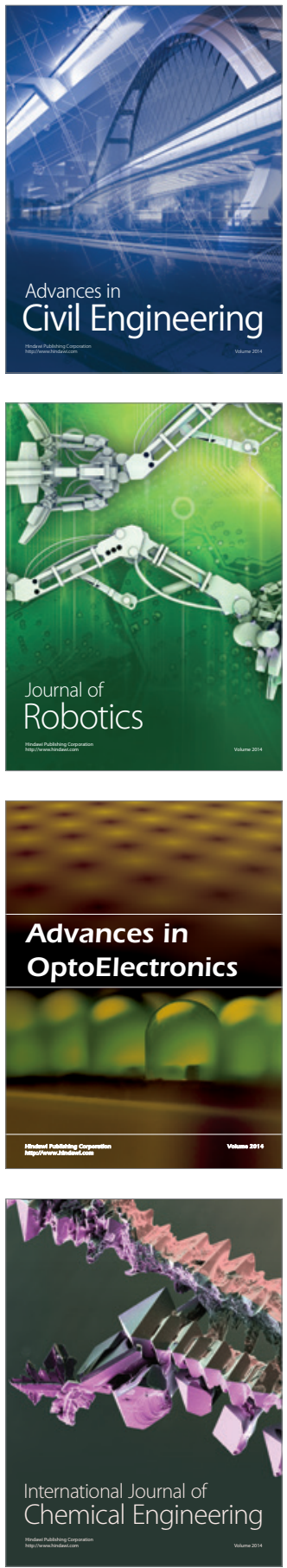

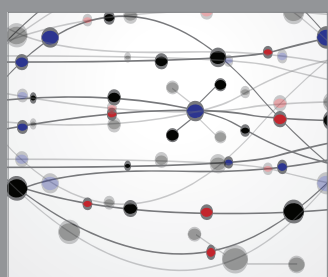

The Scientific World Journal

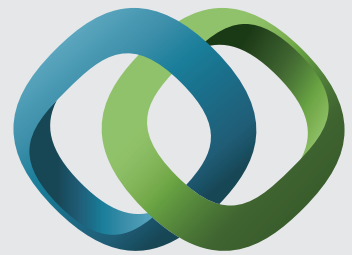

\section{Hindawi}

Submit your manuscripts at

http://www.hindawi.com
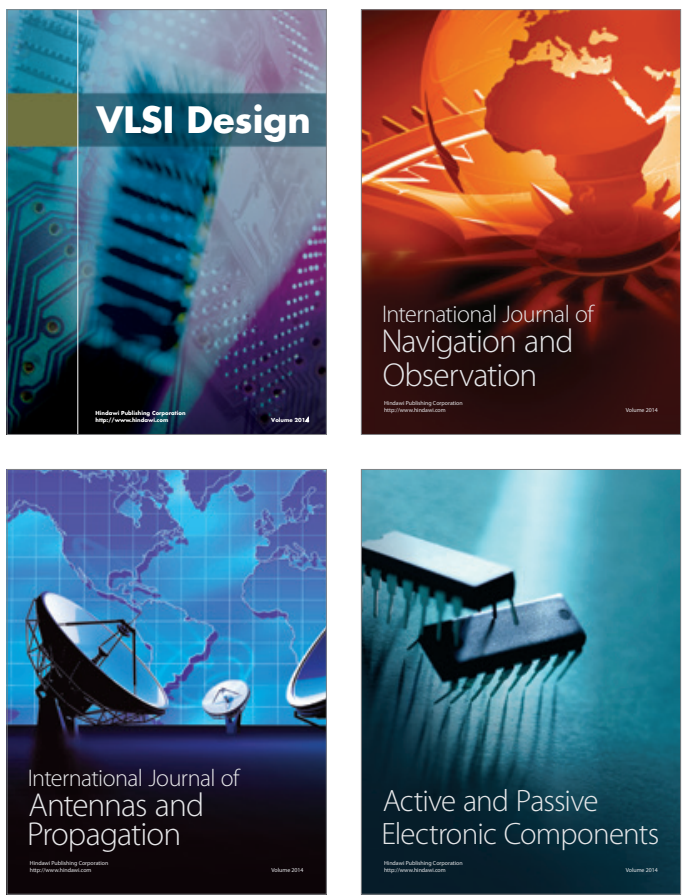
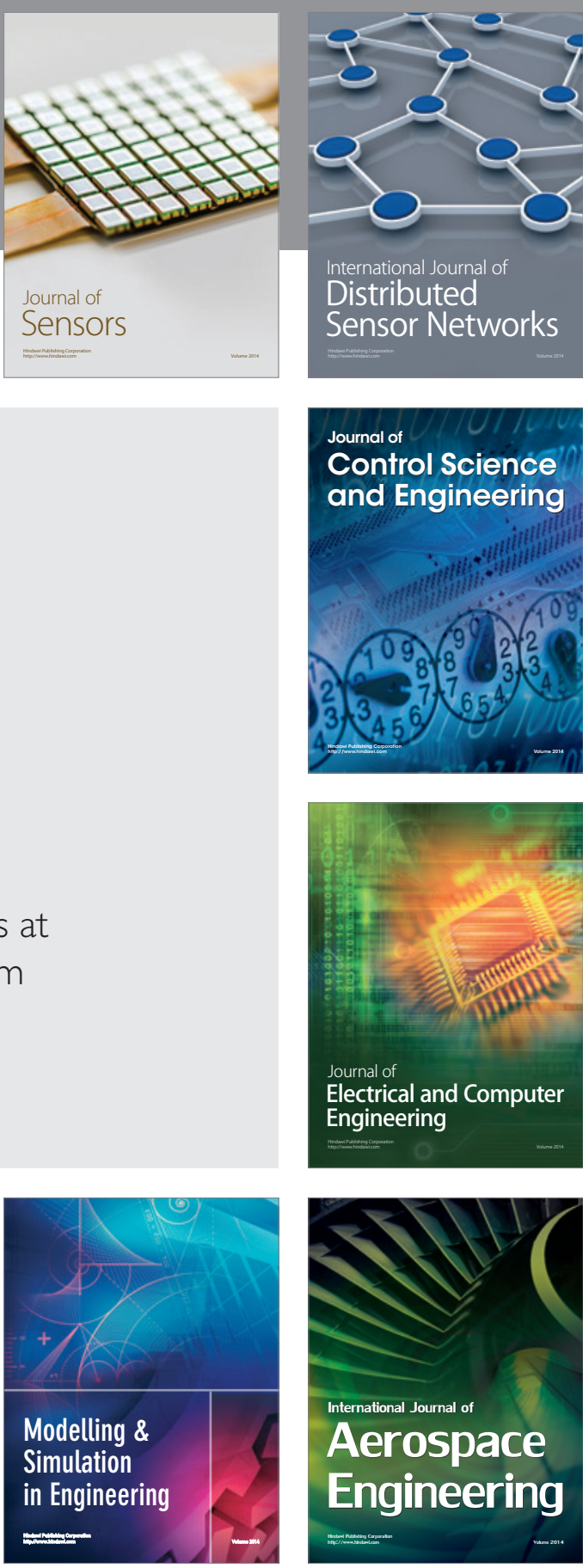

International Journal of

Distributed

Sensor Networks

Journal of

Control Science

and Engineering
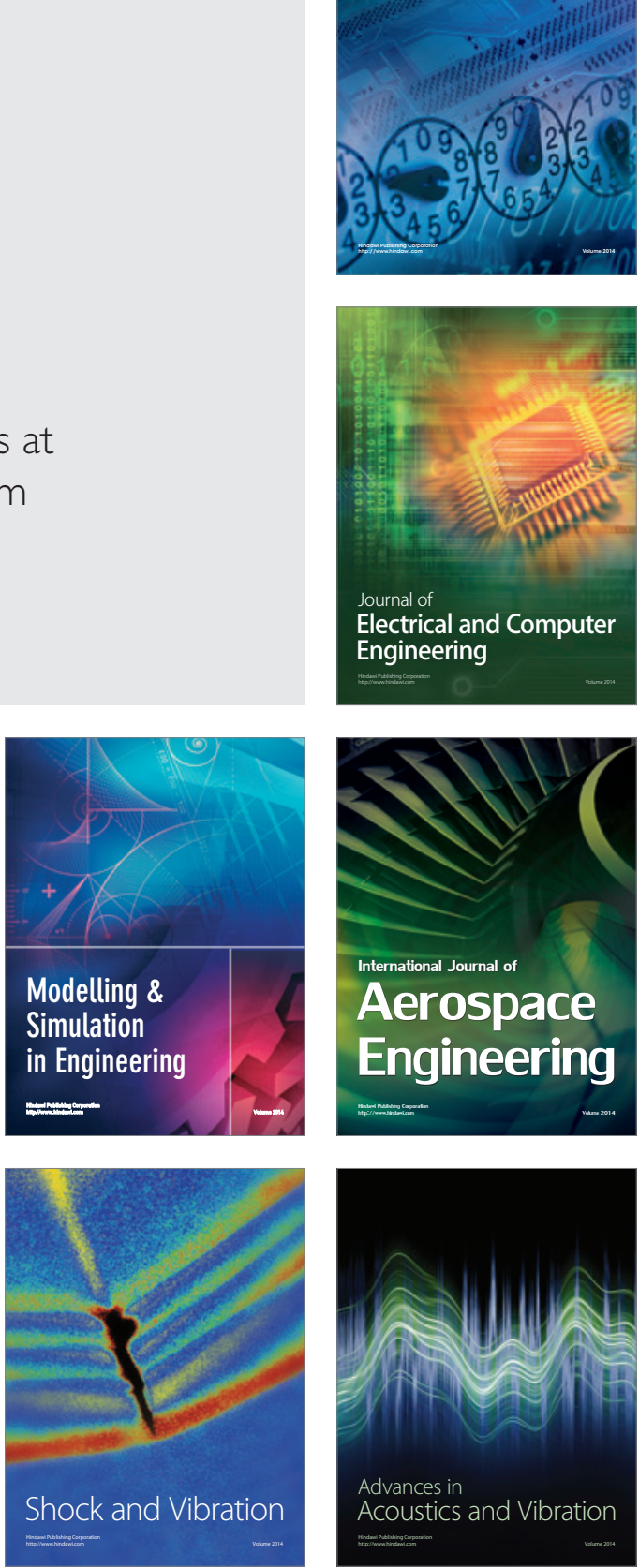